\title{
Lipid metabolism of the Antarctic euphausiid Euphausia crystallorophias and its ecological implications
}

\author{
Gerhard Kattner $^{1, *}$, Wilhelm Hagen ${ }^{2}$
}

'Alfred-Wegener-Institut für Polar- und Meeresiorschung, Postiach 120161, D-27515 Bremerhaven, Germany

${ }^{2}$ Institut für Polarökologie, Universität Kiel, Wischhofstraße 1-3, Gebäude 12, D-24148 Kiel, Germany

\begin{abstract}
Euphausia crystallorophias is the dominant krill species in high-Antarctic waters and thus has to cope with the most extreme environmental conditions of all euphausiids. To study its lipid biochemical adaptations, various developmental stages were collected during different seasons in the southeastern Weddell Sea. Lipids declined from very high levels in the eggs (51.4\% of dry mass) to low levels in the calyptopis larvae and moderate amounts in the furciliae. Postlarval stages accumulated maximum lipid contents $(51.5 \%)$ in autumn, whereas minimum levels of $6.5 \%$ occurred in late winter/early spring. Wax esters were the primary storage lipid in E. crystallorophias, reaching highest amounts in autumn with a mean of $55.6 \%$ of total lipid. They were also the major lipid class in the eggs. The most abundant fatty acid in the immature and adult specimens was 18:1(n-9). In the wax esters this fatty acid accounted for up to $75 \%$ and together with the 18:1(n-7) fatty acid comprised up to $90 \%$ of total wax ester fatty acids. The fatty acid composition of the eggs was very similar to that of the females. The predominance of the 18:1 fatty acids is an extraordinary lipid characteristic within the marine zooplankton community. It was less pronounced in the younger stages, where 16:0, 20:5(n-3) and 22:6(n-3) were also important fatty acids. Together with the 18:1(n-9) fatty acid, the above were generally the principal components of the phospholipids. The alcohol moieties of the wax esters consisted almost exclusively of the 2 saturated shorter-chain fatty alcohols 14:0 and 16:0. Fatty acids and alcohols increased linearly with total lipid mass and total lipid content, independent of developmental stage, sex, region, season and food supply. The predominant 18:1(n-9) fatty acid exhibited the highest accumulation rate, triple that of the second most abundant fatty acid 20:5(n-3). The seasonal and ontogenetic lipid compositions suggest that these energy reserves play an important role in metabolic maintenance during the overwintering period and, in particular, allow reproductive processes to take place in late winter/early spring, independent of primary production.
\end{abstract}

KEY WORDS: Krnl - Euphausids - Lipid storage - Wax esters · Fatty acids and alcohols Overwintering $\cdot$ Reproduction

\section{INTRODUCTION}

Euphausia crystallorophias, the so-called 'ice krill', is the most common euphausiid in Antarctic shelf waters (e.g. John 1936) and the predominant biomass species in the plankton community of the southeastern Weddell Sea (Siegel 1987, Boysen-Ennen et al. 1991). Its high-Antarctic habitat represents one of the most extreme marine environments with respect to tempera-

·E-mail: gkattner@awi-bremerhaven.de ture, ice coverage and seasonal productivity. The life history of E. crystallorophias shows some important deviations from its better known congener, E. superba. E. crystallorophias prefers neritic regions, and it has never been observed inhabiting ice crevices or scraping algae from the underside of the ice in winter/spring (O'Brien 1987, Nordhausen 1994). Its reproductive biology is also different from E. superba: E. crystallorophias spawns about 2 mo earlier, in late winter/ early spring (e.g. Hempel et al. 1979, Fevolden 1980 , Kirkwood 1996, Pakhomov \& Perrissinoto 1996, 1997), and its eggs remain suspended in upper water layers 
(Harrington \& Thomas 1987). Consequently, the early larval stages do not undergo the developmental ascent known from E. superba and Thysanoessa macrura (Marr 1962, Makarov 1979). As compared with the larger E. superba, E. crystallorophias has a shorter life span, i.e. 4 yr for males and 5 yr for females (Siegel 1987).

Little is known about the lipids of Euphausia crystallorophias, their biosynthesis and the ontogenetic accumulation of these energy reserves. Seasonal lipid dynamics of adult $E$. crystallorophias have been studied by Littlepage (1964), who suggested that 'stored lipids serve only to sustain metabolism' during the dark period. The major depot lipids are wax esters (Bottino 1975, Clarke 1984), but phosphatidylcholine has been identified as an additional energy source (Hagen et al. 1996). Few data are available on the fatty acid and alcohol compositions of E. crystallorophias; Bottino $(1974,1975)$ compared the lipid compositions of E. crystallorophias and E. superba from the Ross Sea and described the predominance of oleic acid in the wax esters. Similar results were reported for the fatty acids in one sample of E. crystallorophias from the Weddell Sea (Ellingsen \& Mohr 1981).

To study ontogenetic and seasonal aspects of the lipid metabohism of Euphausia crystallorophias, eggs, larvae, immature and adult stages were collected during various seasons in the Weddell Sea and a large number of lipid and fatty acid/alcohol analyses were carried out over a wide lipid range. Our investigations aimed at clarifying relationships between different fatty acids/alcohols and the amount of lipids and wax esters. The objective was to acquire a better understanding of the biosynthetic and dietary influences on the lipogenesis of E. crystallorophias and to discuss these factors in the light of its life cycle characteristics and its adaptations to the extreme high-Antarctic environment.

\section{MATERIALS AND METHODS}

Specimens of Euphausia crystallorophias were collected in the southeastern Weddell Sea between $70^{\circ}$ and $78^{\circ} \mathrm{S}$ during 'Polarstern' expeditions in summer 1985, late winter/early spring 1986, and autumn 1992 (Fig. 1). Larval to adult E. crystallorophias (<1 to $41 \mathrm{~mm}$ length) were sampled from epipelagic water layers using different plankton and nekton nets [bongo net, $335 \mu \mathrm{m}$; Rectangular Midwater Trawl (RMT) $1+8$, $325 \mu \mathrm{m}$ and $4.5 \mathrm{~mm}$ mesh]. Juveniles ranged from $\geq 13$ to $<19 \mathrm{~mm}$, subadults from $\geq 19$ to $<23 \mathrm{~mm}$ (in accordance with Siegel 1987) and are treated as 'immature specimens' in the text. The specimens were sorted in a cooled lab container at $4^{\circ} \mathrm{C}$, identified to species, and the size, stage and sex were determined. The postlarval krill were frozen individually in glass vials at $-80^{\circ} \mathrm{C}$. The calyptopis and furcilia samples were pooled; samples comprised between 9 and 200 specimens, depending on the stage and size. A gravid female was kept in a $51 \mathrm{jar}$ at $0^{\circ} \mathrm{C}$ until spawning and 1 sample with 300 eggs was collected for lipid analysis In the home laboratory dry mass was measured after lyophilisation for $48 \mathrm{~h}$. Total lipids were extracted with dichloromethane:methanol $(21, v: v$, with $0.01 \%$ butylhydroxytoluene added as antioxidant). The lipid content was determined gravimetrically essentially following Folch et al. (1957).

Lipid classes of individual samples were separated by preparative thin-layer chromatography using hexane: diethylether:formic acid (85:15:0.04, v:v) The lipid classes were visualised under UV light after spraying with $0.1 \% 2,7$-dichlorofluorescein in methanol. The material was eluted from the silica with dichloromethane:methanol $(2: 1, \mathrm{v}: \mathrm{v})$ and its purity confirmed using the latroscan method, which combines thin-layer chromatography and flame ionisation detection (TLCFID).

The fatty acid and fatty alcohol compositions of the total lipid extracts and the lipid classes (phospholipids, wax esters) were determined by gas-liquid chromatography. The fatty acid components of the lipids were converted to their methyl ester derivatives (FAME) by transesterification in methanol containing $3 \%$ concentrated sulphuric acid at $80^{\circ} \mathrm{C}$ for $4 \mathrm{~h}$. The fatty alcohol moieties occurred as free alcohols. After extraction with hexane, FAME and free fatty alcohols were



Fig. 1. Investigation areas during 3 'Polarstern' cruises (ANT III/3, V/3, X/3) in the southeastern Weddell Sra in late wintert early spring, summer and autumn. Dotted areas indicate ice shelves 
simultaneously analysed with a Carlo Erba gas-liquid chromatograph (HRGC 5300) on a $30 \mathrm{~m} \times 0.25 \mathrm{~mm}$ i.d. wall-coated open tubular column (film thickness: $0.25 \mu \mathrm{m}$; liquid phase: DB-FFAP) using temperature programming. FAME and free alcohols were identified using standard mixtures and retention times. The gasliquid chromatographic analysis was performed in accordance with standard methods (for details refer to Kattner \& Fricke 1986). Based on the amount of free alcohols determined by gas-liquid chromatography, wax ester percentages of total lipid were calculated. These data agree well with the wax ester percentages of summer specimens determined by Iatroscan (Hagen 1988).

\section{RESULTS}

\section{Dry mass and total lipid}

The eggs of Euphausia crystallorophias collected during late winter/early spring from a spawned female each weighed $23 \mu \mathrm{g}$ and had a high lipid content of $51.4 \%$ of dry mass (DM). The early larvae, mainly second calyptopes collected during summer, had a mean dry mass of $103 \mu \mathrm{g}$ with low lipid contents of $14.3 \%$ DM. Dry mass of the furcilia stages spanned from 0.26 to $3.27 \mathrm{mg}$, and the lipid contents ranged between 14.7 and 29.4\% DM. Dry mass and lipid mass data of the immature specimens covered a wide range, and the lipid contents showed an ontogenetic and seasonal lipid accumulation with maximum lipid levels of $47.4 \%$ DM accurring in the autumn subadults (Table 1 , Fig. 2A).

Dry mass of adult Euphausia crystallorophias extended from 8.5 to $131.4 \mathrm{mg}$. The females were much heavier (with means above $61 \mathrm{mg}$ DM in winter/spring and autumn) than the males, which reached a maximum in autumn with a mean of $41.3 \mathrm{mg}$. The adults exhibited a pronounced seasonal lipid pattern: The lipid contents varied considerably with the seasons, especially in spring and summer, when lipid comprised from a few percent to half of the dry mass. In contrast, the autumn specimens were generally rich in lipid (Fig. 2B). In January/February (summer) the adults had mean lipid levels of $35.3 \%$ DM, which increased to $43.8 \%$ DM in April/May (autumn). Lowest levels were found in October/November (late winter/early spring) (Table 1). In contrast to the autumn period, significant differences in lipid content were detected between sexes during the late winter/early spring period (Scheffe's F-test, $p<0.05$; Zar 1984). Mean lipid levels of females decreased quite rapidly from $30.2 \%$ in late October to $23.5 \%$ in early November and $15.9 \%$ in late November. Mean lipid levels of males were con-
Table 1. Euphausia crystallorophias. Range, mean \pm standard deviation (SD) of dry mass (DM), lipid mass and total lipid content (in $\%$ DM) of different ontogenetic stages as a function of the season in the southeastern Weddell Sea; $(n)=$ number of samples analysed. Note: immature specimens in a utumn were sub-adults only; females and males in summer were not sexed

\begin{tabular}{|c|c|c|c|}
\hline & $\begin{array}{c}\text { Winter/Spring } \\
\text { Oct/Nov }\end{array}$ & $\begin{array}{l}\text { Summer } \\
\text { Jan/Feb }\end{array}$ & $\begin{array}{l}\text { Autumn } \\
\text { April/May }\end{array}$ \\
\hline Eggs $(n)$ & (1) & $(-)$ & $(-)$ \\
\hline Dry mass (mg) & 0.023 & - & - \\
\hline Lipid mass (mg) & 0.012 & - & - \\
\hline Lipid (\% DM) & 51.4 & - & - \\
\hline Calyptopes I-III ( & $(-)$ & (6) & $(-)$ \\
\hline \multicolumn{4}{|l|}{ Dry mass (mg) } \\
\hline Range & - & $0.064-0.136$ & - \\
\hline Mean $\pm S D$ & - & $0.103 \pm 0.032$ & - \\
\hline \multicolumn{4}{|l|}{ Lipid mass (mg) } \\
\hline Range & - & $0.007-0.030$ & - \\
\hline Mean $\pm S D$ & - & $0.015 \pm 0.009$ & - \\
\hline \multicolumn{4}{|l|}{ Lipid $(\% D M)$} \\
\hline Range & - & $10.3-21.8$ & - \\
\hline Mean $\pm S D$ & - & $14.3 \pm 4.0$ & - \\
\hline Furciliae I-VI (n) & (2) & (6) & (2) \\
\hline \multicolumn{4}{|l|}{ Dry mass (mg) } \\
\hline Range & $1.00 ; 1.51$ & $0.26-3.27$ & $0.72 ; 0.75$ \\
\hline Mean $\pm S D$ & 1.25 & $1.77 \pm 1.31$ & 0.74 \\
\hline \multicolumn{4}{|l|}{ Lipid mass (mg) } \\
\hline Range & $0.32 ; 0.44$ & $0.04-0.69$ & $0.17 ; 0.21$ \\
\hline Mean $\pm S D$ & 0.38 & $0.37 \pm 0.30$ & 0.19 \\
\hline \multicolumn{4}{|l|}{ Lipid (\% DM) } \\
\hline Range & $21.1 ; 22.1$ & $14.7-22.6$ & $22.1 ; 29.4$ \\
\hline Mean $\pm S D$ & 21.6 & $18.6 \pm 3.8$ & 25.8 \\
\hline Immatures (n) & (12) & (11) & (3) \\
\hline \multicolumn{4}{|l|}{ Dry mass (mg) } \\
\hline Range & $4.3-10.6$ & $2.4-17.0$ & $30.0-49.1$ \\
\hline Mean \pm SD & $7.4 \pm 1.6$ & $8.5 \pm 5.3$ & $40.4 \pm 9.7$ \\
\hline \multicolumn{4}{|l|}{ Lipid mass (mg) } \\
\hline Range & $0.8-1.9$ & $0.4-6.3$ & $11.7-23.3$ \\
\hline Mean \pm SD & $1.4 \pm 0.4$ & $2.6 \pm 2.0$ & $18.0 \pm 5.9$ \\
\hline \multicolumn{4}{|l|}{ Lipid (\% DM) } \\
\hline Range & $11.3-27.0$ & $17.9-37.7$ & $39.0-47.4$ \\
\hline Mean $\pm S D$ & $19.1 \pm 5.7$ & $27.3 \pm 6.3$ & $43.9 \pm 4.4$ \\
\hline Females (n) & (37) & $(-)$ & (15) \\
\hline \multicolumn{4}{|l|}{ Dry mass (mg) } \\
\hline Range & $13.7-115.7$ & - & $36.9-101.5$ \\
\hline Mean $\pm S D$ & $64.4 \pm 30.8$ & - & $61.2 \pm 19.4$ \\
\hline \multicolumn{4}{|l|}{ Lipid mass (mg) } \\
\hline Range & $2.0-42.9$ & - & $14.9-47.6$ \\
\hline Mean $\pm S D$ & $17.1 \pm 11.5$ & - & $27.8 \pm 10.1$ \\
\hline \multicolumn{4}{|l|}{ lipid (\% DM) } \\
\hline Range & $11.7-39.4$ & - & $37.2-51.5$ \\
\hline Mean $\pm S D$ & $24.3 \pm 7.8$ & - & $45.1 \pm 4.4$ \\
\hline \multirow{2}{*}{\multicolumn{4}{|c|}{ Dry mass (mg) }} \\
\hline & & & \\
\hline Range & $8.5-47.9$ & - & $26.7-67.3$ \\
\hline Mean $\pm S D$ & $31.3 \pm 11.0$ & - & $41.3 \pm 12.8$ \\
\hline \multicolumn{4}{|l|}{ Lipid Inass (mg) } \\
\hline Range & $1.6-9.7$ & - & $11.8-28.3$ \\
\hline Mean $+S D$ & $4.1 \pm 2.3$ & - & $17.4 \pm 5.2$ \\
\hline \multicolumn{4}{|l|}{ Lipid (\% DM) } \\
\hline Range & $6.5-24.9$ & - & $36.0-47.3$ \\
\hline Mean $\pm S D$ & $13.5 \pm 6.3$ & - & $42.3 \pm 2.8$ \\
\hline All adults $(n)$ & (55) & $(44)$ & (28) \\
\hline Dry mass (mg) & & & \\
\hline Range & $8.5-115.7$ & $17.2-131.4$ & $26.7-101.5$ \\
\hline Mean \pm SD & $53.6 \pm 30.3$ & $48.4 \pm 28.2$ & $52.0 \pm 19.3$ \\
\hline Lipid mass (mg) & & & \\
\hline Range & $1.6-42.9$ & $1.5-61.0$ & $11.8-47.6$ \\
\hline Mean \pm SD & $12.8 \pm 11.3$ & $18.0 \pm 13.4$ & $23.0 \pm 9.6$ \\
\hline Lipid (\% DM) & & & \\
\hline Range & $6.5-39.4$ & $8.9-48.2$ & $36.0-51.5$ \\
\hline Mean \pm SD & $20.7 \pm 8.9$ & $35.3 \pm 7.8$ & $43.8 \pm 3.9$ \\
\hline
\end{tabular}



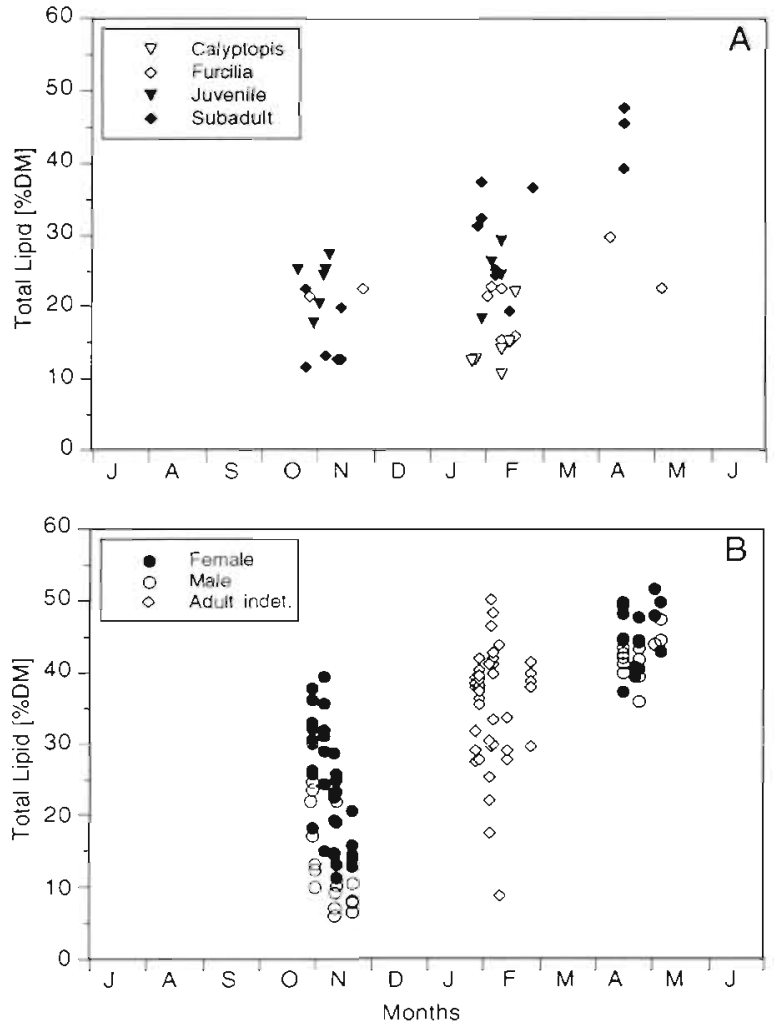

Fig. 2. Euphausia crystallorophias. Seasonal lipid accumulation and depletion (A) in larvae to subadults and (B) in adults from the southeastern Weddell Sea. DM: dry mass; indet.: sex not determined siderably lower and declined from $18.0 \%$ in late October to $11.3 \%$ and $8.6 \%$ DM in November (Fig. 2B).

\section{Wax esters}

The ontogenetic and seasonal changes in the total lipid (TL) levels of Euphausia crystallorophias are largely explained by the mobilisation and accumulation of wax esters. The lipid-rich eggs from late winter/early spring contained high wax ester levels of $61.8 \% \mathrm{TL}$, whereas the calyptopis larvae collected in summer had a low mean wax ester content of $13.7 \%$ TL. The wax ester levels were slightly higher in the furciliae from spring and summer and reached a maximum of $34.4 \%$ TL in autumn. A similar seasonal tendency, but on a higher level, was apparent for the immature specimens, which had maximum wax ester levels of $53.5 \%$ TL in autumn (Table 2). For the adults, pronounced differences between sexes became evident during late winter/early spring: While females had mean wax ester contents of $47.4 \%$ TL, males exhibited much lower percentages of $24.3 \%$ TL on average (Table 3 ), ranging from 7.9 to $51.4 \%$ TL. This corresponds to the highly variable changes in total lipid content mentioned above. During the summer expedition, when sexes were not separated, the wax ester levels resembled those of the spring females, and the low variability did not indicate significant differences between sexes during summer. This is also supported by the wax

Table 2. Euphausia crystallorophias. Compositions of major fatty acids and alcohols (mass percent) of eggs and younger developmental stages from various seasons. WE $(\% \mathrm{TL})$ : wax esters as percent of total lipid; $\mathrm{SD}$ : standard deviation; $(\mathrm{n})=$ number of samples

\begin{tabular}{|c|c|c|c|c|c|c|c|c|}
\hline & \multirow{2}{*}{$\begin{array}{c}\text { Eggs } \\
\text { W:nter/Spring } \\
\text { (1) }\end{array}$} & \multirow{2}{*}{$\begin{array}{l}\text { Calyptopes } \\
\text { Summer } \\
\text { Mean } \pm \text { SD (6) }\end{array}$} & \multicolumn{3}{|c|}{ Furciliae } & \multicolumn{3}{|c|}{ Immatures } \\
\hline & & & $\begin{array}{c}\text { Winter/Spring } \\
\text { (1) }\end{array}$ & $\begin{array}{l}\text { Summer } \\
\text { Mean (2) }\end{array}$ & $\begin{array}{l}\text { Autumn } \\
\text { Mean (2) }\end{array}$ & $\begin{array}{c}\text { Winter/Spring } \\
\text { (1) }\end{array}$ & $\begin{array}{c}\text { Summer } \\
\text { Mean } \pm \text { SD }(8)\end{array}$ & $\begin{array}{c}\text { Autumn } \\
\text { Mean (2) }\end{array}$ \\
\hline \multicolumn{9}{|l|}{ Fatty acids } \\
\hline $14: 0$ & 0.7 & $4.2 \pm 0.5$ & 3.8 & 4.0 & 3.2 & 1.7 & $2.3 \pm 0.5$ & 1.9 \\
\hline $16: 0$ & 9.0 & $13.9 \pm 0.6$ & 12.7 & 14.2 & 13.3 & 14.1 & $12.4 \pm 1.6$ & 11.6 \\
\hline $16: 1(n-7)$ & 6.6 & $3.9 \pm 1.0$ & 6.5 & 4.1 & 1.6 & 4.4 & $6.4 \pm 2.9$ & 6.6 \\
\hline $18: 0$ & 0.8 & $0.8 \pm 0.2$ & 0.9 & 1.0 & 1.2 & 0.7 & $0.8 \pm 0.1$ & 0.8 \\
\hline $18: 1(n-9)$ & 40.0 & $10.7 \pm 2.3$ & 18.3 & 10.7 & 18.1 & 26.9 & $26.2 \pm 4.1$ & 32.5 \\
\hline $18: 1(n-7)$ & 10.5 & $6.7 \pm 0.9$ & 8.8 & 6.8 & 7.1 & 12.4 & $11.5 \pm 0.7$ & 11.7 \\
\hline $18: 2(n-6)$ & 1.6 & $2.2 \pm 0.6$ & 1.6 & 1.4 & 2.2 & 1.4 & $1.7 \pm 0.1$ & 1.9 \\
\hline $18: 3(n-3)$ & 0.6 & $1.0 \pm 0.4$ & 0.3 & 1.2 & 0.9 & 0.3 & $0.6 \pm 0.2$ & 1.0 \\
\hline $18: 4(\mathrm{n}-3)$ & 0.5 & $5.4 \pm 2.5$ & 0.8 & 7.0 & 10.9 & 1.0 & $2.2 \pm 0.7$ & 3.6 \\
\hline $20: 1^{\mathrm{d}}$ & 2.6 & $0.8 \pm 0.1$ & 4.7 & 0.5 & 2.7 & 1.2 & $0.9 \pm 0.3$ & 1.3 \\
\hline $20: 4^{b}$ & 0.3 & $1.3 \pm 0.1$ & 1.4 & 1.3 & 1,4 & 1.5 & $1.1 \pm 0.2$ & 0.8 \\
\hline $20: 5(n-3)$ & 11.8 & $27.9 \pm 5.1$ & 18.0 & 28.4 & 18.9 & 21.6 & $20.4 \pm 2.0$ & 16.3 \\
\hline $22: 1^{c}$ & 6.5 & $1.5 \pm 1.1$ & 5.0 & 0.2 & 0.3 & 0.1 & $0.1 \pm 0.1$ & 0.7 \\
\hline $22: 6(n-3)$ & 7.1 & $17.7 \pm 2.6$ & 16.1 & 17.1 & 17.6 & 12.2 & $10.7 \pm 2.0$ & 8.5 \\
\hline \multicolumn{9}{|l|}{ Alcohols } \\
\hline $14: 0$ & 56.4 & $60.6 \pm 3.2$ & 48.9 & 66.9 & 66.9 & 61.1 & $64.6 \pm 1.5$ & 63.9 \\
\hline $16: 0$ & 37.3 & $37.5 \pm 2.1$ & 51.1 & 33.1 & 30.7 & 35.8 & $34.8 \pm 1.3$ & 33.2 \\
\hline $20: 1(n-9)$ & 1.2 & $1.9 \pm 2.2$ & - & - & 2.4 & 3.2 & $0.4 \pm 0.8$ & 1.5 \\
\hline $22: 1(n-11)$ & 1.9 & - & - & - & - & - & - & - \\
\hline WE $(\%$ TL) & 61.8 & $13.7 \pm 2.7$ & 17.3 & 16.4 & 34.4 & 31.9 & $38.2 \pm 7.8$ & 53.5 \\
\hline
\end{tabular}


Table 3. Euphausia crystallorophias. Compositions of major fatty acids and alcohols (mass percent) of adults from various seasons. WE $(\%$ TL): wax esters as percent of total lipid; SD: standard deviation; $(n)=$ number of samples

\begin{tabular}{|c|c|c|c|c|}
\hline & $\begin{array}{c}\text { Females } \\
\text { Winter/Spring } \\
\text { Mean } \pm \text { SD (11) }\end{array}$ & $\begin{array}{c}\text { Males } \\
\text { Winter/Spring } \\
\text { Mean } \pm \text { SD }(7)\end{array}$ & $\begin{array}{c}\text { Adults } \\
\text { Summer } \\
\text { Mean } \pm \mathrm{SD}(13)\end{array}$ & $\begin{array}{c}\text { Adults } \\
\text { Autumn } \\
\text { Mean } \pm \text { SD (11) }\end{array}$ \\
\hline \multicolumn{5}{|l|}{ Fatty acids } \\
\hline $14: 0^{\circ}$ & $1.5 \pm 0.2$ & $1.5 \pm 0.2$ & $1.9 \pm 0.3$ & $1.7 \pm 0.2$ \\
\hline $16: 0$ & $11.4 \pm 1.1$ & $13.9 \pm 0.8$ & $11.8 \pm 0.4$ & $11.8 \pm 0.4$ \\
\hline $16: 1(n-7)$ & $6.0 \pm 2.5$ & $2.9 \pm 1.8$ & $7.9 \pm 2.6$ & $6.1 \pm 1.3$ \\
\hline 18:0 & $0.6 \pm 0.1$ & $0.8 \pm 0.2$ & $0.8 \pm 0.2$ & $0.7 \pm 0.1$ \\
\hline $18: 1(n-9)$ & $37.7 \pm 5.4$ & $22.2 \pm 6.7$ & $35.7 \pm 5.0$ & $35.6 \pm 1.9$ \\
\hline $18: 1(n-7)$ & $10.9 \pm 1.1$ & $9.8 \pm 2.0$ & $11.5 \pm 1.0$ & $11.8 \pm 0.5$ \\
\hline $18: 2(n-6)$ & $1.5 \pm 0.2$ & $1.5 \pm 0.1$ & $1.5 \pm 0.1$ & $1.4 \pm 0.2$ \\
\hline $18: 3(n-3)$ & $0.4 \pm 0.1$ & $0.5 \pm 0.1$ & $0.5 \pm 0.2$ & $0.8 \pm 0.1$ \\
\hline $18: 4(n-3)$ & $0.6 \pm 0.2$ & $0.5 \pm 0.2$ & $1.7 \pm 1.1$ & $3.4 \pm 1.3$ \\
\hline $20: 1^{\mathrm{a}}$ & $1.0 \pm 0.3$ & $0.7 \pm 0.2$ & $0.9 \pm 0.3$ & $1.3 \pm 0.6$ \\
\hline $20: 4^{b}$ & $0.9 \pm 0.3$ & $1.6 \pm 0.4$ & $0.9 \pm 0.2$ & $0.4 \pm 0.1$ \\
\hline $20: 5(n-3)$ & $16.5 \pm 3.0$ & $23.0 \pm 2.6$ & $16.7 \pm 2.6$ & $14.7 \pm 0.8$ \\
\hline $22: 1^{c}$ & $0.4 \pm 0.2$ & $0.4 \pm 0.4$ & $0.3 \pm 0.2$ & $0.6 \pm 0.2$ \\
\hline $22: 6(n-3)$ & $10.1 \pm 3.0$ & $20.0 \pm 7.0$ & $7.3 \pm 2.6$ & $8.8 \pm 1.1$ \\
\hline \multicolumn{5}{|l|}{ Alcohols } \\
\hline $14: 0$ & $62.6 \pm 4.9$ & $56.5 \pm 9.2$ & $64.0 \pm 3.4$ & $64.1 \pm 2.9$ \\
\hline $16: 0$ & $35.6 \pm 3.9$ & $40.1 \pm 7.1$ & $34.7 \pm 2.7$ & $33.1 \pm 2.2$ \\
\hline $20: 1(n-9)$ & $0.4 \pm 0.7$ & $1.5 \pm 3.7$ & $0.2 \pm 0.5$ & $1.5 \pm 0.7$ \\
\hline $22: 1(n-11)$ & - & $1.7 \pm 4.4$ & - & - \\
\hline$W E(\% \mathrm{TL})$ & $47.4 \pm 8.2$ & $24.3 \pm 15.3$ & $46.6 \pm 4.4$ & $55.6 \pm 2.6$ \\
\hline
\end{tabular}

ester data for the autumn specimens, when percentages were similar for both sexes. Again, maximum levels were reached during autumn with means of $56.6 \%$ for the females and $53.0 \%$ for the males. Fig. 3 depicts the general relationship between total lipid content ( $\%$ DM) and wax ester percentage (\% TL) for all stages and seasons. The fitted curve shows a strong initial increase in wax esters with increasing total lipid content, which levels off at a 'saturation' of about $50 \%$, corresponding to a total lipid content of about $40 \%$ DM.

\section{Fatty acids and alcohols}

Analyses were carried out on the total lipid extracts of all samples. In addition, representative samples were selected for separate analyses of the fatty acid and alcohol compositions of the major lipid classes.

\section{Total lipid extracts}

The 5 principal fatty acids $16: 0,18: 1(n-9), 18: 1(n-7)$, $20: 5(n-3)$ and 22:6(n-3), generally accounted for almost $90 \%$ of all fatty acids in the total lipid extract, with 18:1(n-9) predominating, especially in the lipid-rich eggs and in the older stages. The fatty acids $16: 1(n-7)$ and 18:4(n-3) occurred in higher percentages only in some stages and seasons.
The lipid compositions of the early developmental stages, calyptopes and furciliae, were dominated by the polyunsaturated fatty acids 20:5(n-3) and 22:6(n-3) with 20:5(n-3) prevailing in the lipid-poor specimens. Other major components were 18:1(n-9) and 16:0, the former strongly increasing in abundance with increasing lipid content (Fig, 4). In summer and autumn, $18: 4(n-3)$ reached up to $11 \%$, whereas in spring 16:1(n-7) was slightly more abundant (Table 2). With advancing development from furciliae to immature stages, $18: 1(n-9)$ became the predominant fatty acid

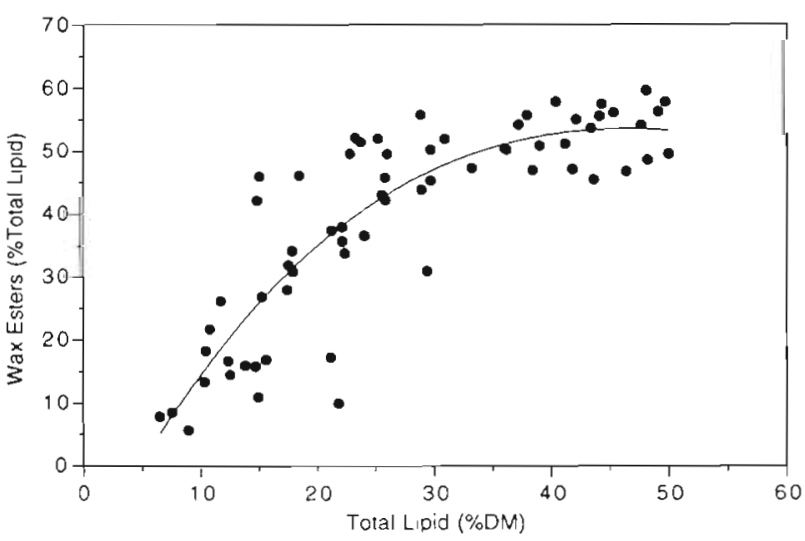

Fig. 3. Euphausia crystallorophias (larvae to adults). Accumulation of wax esters (in percent of total lipid) with increasing total lipid content (in percent of dry mass, DM) 
followed by $20: 5(n-3)$. The 2 isomers $18: 1(n-9)$ and $18: 1(n-7)$ made up about $4.0 \%$ of the fatty acids in the total lipid extract of the immature specimens during all seasons. Corresponding to the maximum lipid and wax ester levels in autumn, 18:1(n-9) also reached highest percentages prior to overwintering (Table 2), comparable to those of the adults. The fatty acid compositions of the adults were very similar during the seasons, except for the less lipid-rich males in spring. These males were characterized by high percentages of the polyunsaturated fatty acids 20:5(n-3) and 22:6(n-3), which comprised $43 \%$, whereas the 18:1(n-9) and $(n-7)$ fatty acids made up only one third of the fatty acids. In contrast, these isomers comprised nearly half of the fatty acids in the lipid-rich adults from summer and autumn and in the females from late winter/early spring (Table 3). The fatty acid and alcohol composition of the eggs spawned in November resembled that of the lipid and wax ester-rich females in late winter/early spring, again with the $18: 1(n-9)$ and $(n-7)$ isomers predominating with 40.0 and $10.5 \%$, respectively (Tables $2 \& 3$ ).

\section{Lipid classes}

Fatty acid analyses of the major lipid classes showed essentially similar compositions for the total lipid extracts of the calyptopes and furciliae, except for the wax esters of the furciliae (Table 4). The phospholipids were rich in the polyunsaturated fatty acids 20:5(n-3) and 22:6(n-3). The triacylglycerols contained less 22:6(n-3) as compared with the total lipid extract. This was compensated by higher proportions of various other fatty acids. High amounts of the 18:4(n-3) fatty acid were found in the triacylglycerols, especially in the furciliae, where it was $15.4 \%$ of the total fatty acids. The wax ester composition of the calyptopes was similar to that of the total lipid extract. Starting with the furciliae, clear differences occurred between wax esters and total lipid extract, especially due to the predominance of the fatty acid 18:1(n-9) (Table 4).

The phospholipids of the postlarval specimens were generally dominated by the same principal fatty acids as in the larvae, but with higher amounts of 18:1(n-9). In the triacylglycerols the dominance of the 18:1 fatty acids was much more pronounced than in the phospholipids, especially in the immature specimens with $39.9 \%$ for the $(n-9)$ and $12.8 \%$ for the $(n-7)$ isomer. In adults other important components of the triacylglycerols were the $16: 1(n-7)$ and the 18:4(n-3) fatty acids. The wax esters were clearly dominated by the 18:1(n-9) fatty acid, particularly in the immature specimens, with values up to $75.0 \%$, and in the adults, with $65.2 \%$, followed by $18: 1(n-7)$ and smaller amounts of $16: 1(n-7)$. Polyunsaturated and saturated fatty acids only occurred in very small or in trace amounts in the immature and adult specimens (Table 4).

Table 4. Euphausia crystallorophias. Lipid class compositions of major fatty acids and alcohols (mass percent), exemplified for various developmental stages. PL: phospholipids; TAG: triacylglycerols; WE: wax esters

\begin{tabular}{|c|c|c|c|c|c|c|c|c|c|c|c|c|}
\hline & \multicolumn{3}{|c|}{ Calyptopes } & \multicolumn{3}{|c|}{ Furciliae } & \multicolumn{3}{|c|}{ Immatures } & \multicolumn{3}{|c|}{ Adults } \\
\hline & $\mathrm{PL}$ & TAG & WE & $\mathrm{PL}$ & TAG & WE & PL & TAG & WE & PL & TAG & WE \\
\hline \multicolumn{13}{|l|}{ Fatty acids } \\
\hline $14: 0$ & 1.8 & 6.3 & 3.7 & 2.9 & 4.0 & 1.5 & 3.0 & 4.0 & 0.2 & 2.4 & 9.4 & 0.4 \\
\hline $16: 0$ & 18.6 & 14.5 & 22.0 & 19.5 & 10.1 & 4.7 & 21.1 & 24.9 & 0.4 & 22.2 & 18.5 & 0.5 \\
\hline $16: 1(n-7)$ & 1.7 & 7.9 & 2.6 & 2.5 & 9.0 & 4.7 & 3.7 & 2.1 & 5.8 & 5.5 & 15.2 & 7.6 \\
\hline $18: 0$ & 1.5 & 3.7 & 1.5 & 1.7 & 3.1 & 3.3 & 0.7 & 4.7 & - & 1.0 & 2.1 & 0.2 \\
\hline $18: 1(n-9)$ & 6.8 & 11.4 & 7.8 & 7.1 & 12.5 & 34.2 & 19.5 & 39.9 & 75.0 & 14.6 & 20.3 & 65.2 \\
\hline $1.8: 1(n-7)$ & 9.4 & 8.5 & 8.6 & 7.8 & 6.0 & 16.1 & 7.7 & 12.8 & 15.5 & 5.4 & 6.5 & 20.2 \\
\hline $18: 2(n-6)$ & 1.5 & 2.7 & 2.3 & 2.1 & 3.5 & 3.0 & 2.1 & 1.5 & 1.6 & 1.1 & 1.2 & 1.2 \\
\hline $18: 3(n-3)$ & 0.4 & 0.7 & 1.2 & 0.8 & 1.4 & 1.7 & 0.7 & - & - & 1.0 & 1.0 & 0.4 \\
\hline $18: 4(n-3)$ & 1.3 & 5.5 & 3.8 & 2.5 & 15.4 & 6.6 & - & - & 0.2 & 3.0 & 7.2 & 1.1 \\
\hline $20: 1^{\star}$ & 0.9 & 2.0 & 1.0 & 0.8 & 3.5 & - & - & 1.4 & 0.7 & 0.5 & 1.4 & 2.6 \\
\hline $20: 4^{b}$ & 0.7 & - & 0.8 & 0.9 & 0.3 & 1.3 & 1.1 & 1.4 & - & 0.7 & 0.1 & - \\
\hline $20: 5(n-3)$ & 32.9 & 20.1 & 23.8 & 28.5 & 16.9 & 18.4 & 23.1 & 4.1 & 0.2 & 26.9 & 8.6 & 0.3 \\
\hline $22: 1^{c}$ & 0.8 & - & 0.8 & 0.7 & 0.4 & - & - & - & - & 0.1 & 0.1 & - \\
\hline $22: 6(n-3)$ & 21.2 & 8.6 & 18.8 & 21.0 & 6.4 & 4.5 & 17.3 & 2.3 & - & 15.4 & 4.5 & 0.1 \\
\hline \multicolumn{13}{|l|}{ Alcohols } \\
\hline $14: 0$ & & & 45.1 & & & 74.1 & & & 71.1 & & & 63.2 \\
\hline $16: 0$ & & & 54.9 & & & 25.9 & & & 28.0 & & & 33.6 \\
\hline $20: 1(n-9)$ & & & - & & & - & & & - & & & 1.9 \\
\hline $22: 1(n-11)$ & & & - & & & - & & & - & & & 0.2 \\
\hline
\end{tabular}



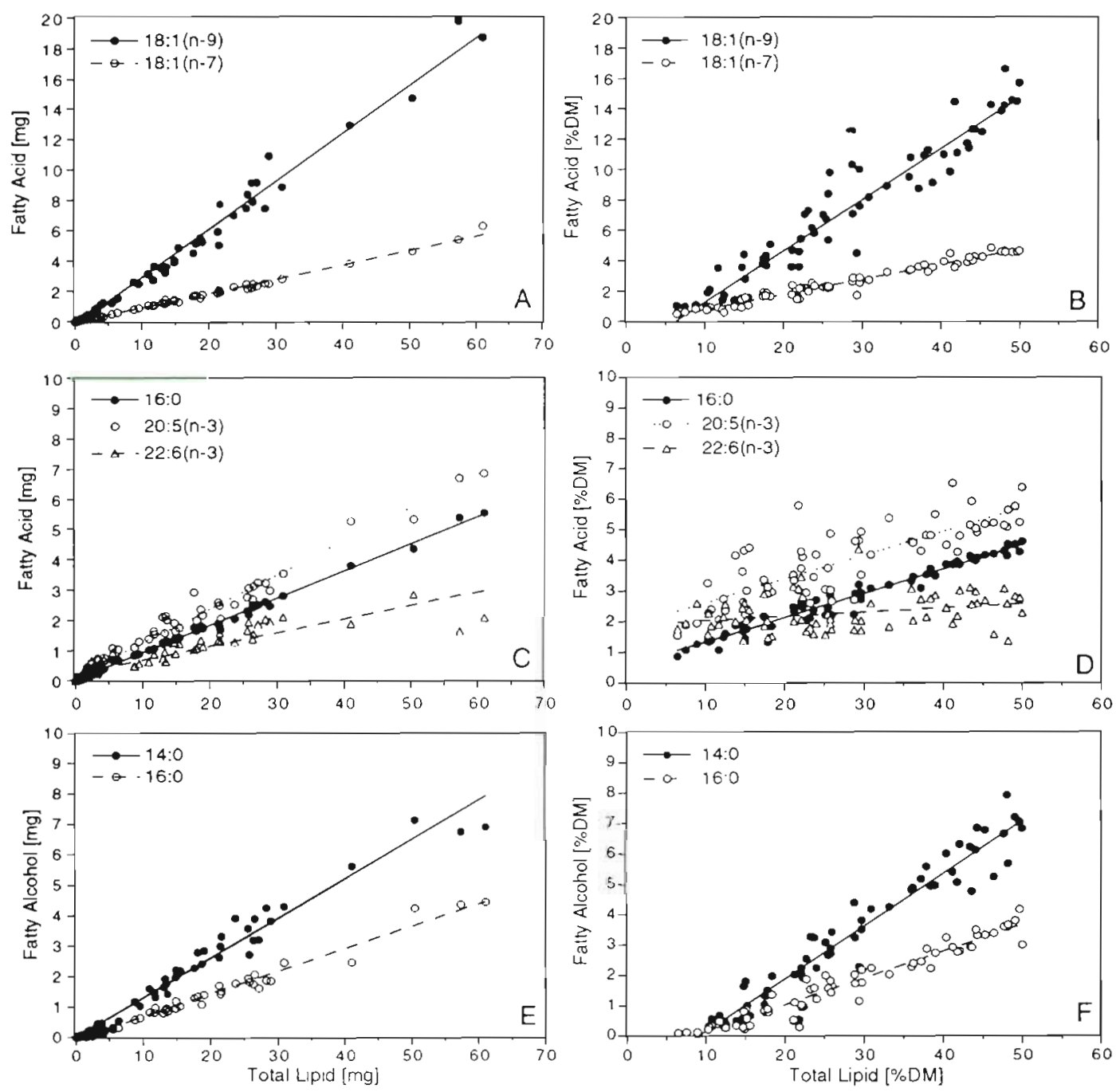

Fig. 4. Euphausia crystallorophias (larvae to adults). Linear accumulation curves of (A, C, E) major fatty acids and alcohols with increasing lipid mass and $(B, D, F)$ total lipid content. DM: dry mass

The fatty alcohol composition of the wax esters was very uniform, except for slight differences in the spring furciliae. Throughout the various stages and seasons, the dominant alcohols, 14:0 and 16:0, comprised more than $90 \%$ of total fatty alcohols. 14:0 usually accounted for two-thirds of the total, while 16:0 made up most of the remaining alcohols, together with small amounts of 20:1(n-9) and 22:1(n-11) (Tables $3 \& 4$ ).

\section{Lipid accumulation}

To illustrate the accumulation patterns of the major fatty acids and alcohols, linear regression curves were calculated (in spite of their interrelationships with total lipid mass and lipid content). Fatty acj.ds of specimens from various stages, seasons and locations exhibited strong linear relationships with their total lipid mass
(Fig. 4A, C, E). The predominant 18:1(n-9) fatty acid showed the highest accumulation rate, triple that of the second most abundant fatty acid, 20:5(n-3), followed by $18: 1(n-7)$ and $16: 0$. The increase in $22: 6(n-3)$ and the minor fatty acids, $16: 1(n-7)$ and $18: 4(n-3)$, was less pronounced and more variable. The slope of the prevailing fatty alcohol, 14:0, was similar to that of the 20:5(n-3) fatty acid, whereas the slope of the 16:0 alcohol was only half of that. The slopes doubled for both alcohols when their fatty alcohol mass was correlated to wax ester mass.

The relationships between fatty acids and alcohols as compared to total lipid content (both expressed in percent of dry mass and hence independent of the mass of the specimens) revealed important characteristics (Fig. 4B, D, F). The strong accumulation of the 18:1(n-9) fatty acid and the 14:0 alcohol was again evident. The extrapolation of fatty acid and alcohol per- 
centages to zero (crossing the $x$-axis) demonstrated the different characteristics of storage and membrane compounds: The accumulation of the typical depot fatty acids and alcohols usually did not start below a lipid level of 6 to $9 \%$ DM. In contrast to the storage compounds, the major phospholipid fatty acids, 20:5(n-3), 22:6(n-3) and 16:0, were always present; hence, minimum essential levels were maintained even at very low lipid levels. Their accumulation rates did not reach those of the 18:1 isomers and the alcohols; 22:6(n-3), in particular, remained almost constant.

\section{DISCUSSION}

\section{Life history traits}

Until now, only very limited information exists on the lipid biochemistry of the Antarctic 'ice krill' Euphausia crystallorophias with regard to life strategies and energetic adaptations. In the Ross Sea, Littlepage (1964) investigated the changes in total lipid levels of adult specimens from May to January. Based on the steady decline of lipid levels during winter, he suggested that lipid reserves are only utilised for metabolic requirements during the dark period, but not for reproductive processes. However, he did not determine the sex of the specimens. In contrast, investigations on Euphausia superba have shown that spawning accounts for a substantial loss of energy (Clarke 1980, Nicol et al. 1995). Comprehensive studies on the other dominant Antarctic euphausiid Thysanoessa macrura also emphasised the central role of lipids for reproductive processes (Hagen \& Kattner in press).

Euphausia crystallorophias is known to spawn mainly in November/December (Littlepage 1964, Hempel et al. 1979, Fevolden 1980, Harrington \& Thomas 1987, Pakhomov \& Perissinotto 1996) and eggs, nauplii and metanauplii were present during our winter/spring Weddell Sea expedition in 1986 (Mizdalski 1988). In early November we observed a large number of females with blue ovaries, according to Harrington \& Thomas (1987) a clear indication that eggs were to be released within 1 to $3 \mathrm{~d}$. The pronounced decrease in lipids during this period may well be associated with reproductive processes, which could also explain the marked differences in lipid levels between sexes during spring. Stepnik (1982) reported that the males of E. crystallorophias start to mature in April, whereas sexual maturation in the females commences 3 mo later in July. This extended process in the males, possibly together with intense mating activities, may account for the lower lipid levels in male E. crystallorophias during early spring. The Weddell Sea females seem to reach minimum lipid levels when egg laying is completed. Hence, in contrast to E. superba (Hagen et al. 1996) but similar to Thysanoessa macrura (Hagen \& Kattner in press), reproduction seems to be largely independent of primary production in E. crystallorophias. The final spawning period may, however, overlap with the beginning phytoplankton bloom in late November/early December (Scharek et al. 1994), and the algal blooms will mainly be utilised by the adults to replenish their depleted lipid reserves. During their life cycle males are reported to spawn twice and females 3 times (Pakhomov \& Perissinotto 1996).

According to Littlepage (1964), adult Euphausia crystallorophias feed on phytoplankton and therefore rely on lipid reserves for metabolic maintenance during winter. Kittel \& Ligowski (1980) also describe the species as a filter feeder which mainly ingests phytoplankton, although the filtering apparatus is much smaller and the 'meshes' coarser as compared to $E$. superba (Brinton \& Townsend 1991). Pelagic diatoms predominated the gut contents of E. crystallorophias in February, but Kittel \& Ligowski (1980) also identified benthic diatoms in these specimens. More recent investigations indicate that the species may switch from algae to other food sources. Gut content analyses revealed phytoplankton, protozoans and metazoans as food items, with a higher occurrence of tintinnids and metazoans in the larger specimens (Hopkins 1987). There are no feeding observations available from the winter period. In contrast to E. superba, E. crystallorophias does not feed directly on the available ice algae (O'Brien 1987), and phytoplankton was too scarce to support feeding in the water column (Marschall 1988). Apart from sinking ice algae, O'Brien (1987) suggested smaller zooplankton and fecal pellets of larger species as possible food sources in early spring, when E. crystallorophias apparently occupies a trophic niche different from E. superba.

Although Euphausia crystallorophias seems to be omnivorous and might utilise zooplankton and other food sources during the dark season, the pronounced seasonal deposition and mobilisation of lipids underscore the importance of extensive energy reserves in the life cycle of E. crystallorophias. Since winter data on feeding and metabolic rates are lacking for this euphausiid, its potential metabolic energy sources (lipids, diet; in combination with quiescence?) and sinks (maintenance, reproduction) during the dark season cannot be quantified. The lipid data from the Weddell Sea indicate that lipid depletion rates in the females are about 5 times higher (about 2 times in males) between late October and late November, as compared to the overwintering period, in spite of the fact that dietary input probably becomes more important during this early spring period. Hence, in E. crys- 
tallorophias lipid reserves seem to play an important role not only for overwintering-as suggested by Littlepage (1964)-but in particular for reproductive success, independent of primary production. Similar findings have been reported for Thysanoessa macrura, which spawns even earlier than $E$. crystallorophias (Hagen \& Kattner in press). The maximum lipid content of E. crystallorophias in autumn appears to be a prerequisite for providing energy for both survival during the food-limited dark season as well as sexual maturation and early spawning prior to the spring bloom. The early timing of reproduction has the advantage that the larval stages can make full use of the entire productive season in order to build up sufficient mass and energy depots to endure the winter as furciliae.

In contrast to the other dominant Antarctic euphausiids, Euphausia superba and Thysanoessa macrura, the eggs of E. Crystallorophias are buoyant (Harrington \& Thomas 1987). Their buoyancy can be explained by the very high lipid and wax ester levels, which are less dense than triacylglycerols. No comparison can be made with the wax ester-storing $T$. macrura, since compositional data are not available for its eggs. The primarily triacylglycerol-storing $E$. superba produces less lipid-rich eggs, which sink to great depths. Apparently, they consist of phospholipids and triacylglycerols, as indicated by the ovarial composition (Clarke 1980). The transfer of wax esters into the eggs is usually not found in wax ester-rich calanoid copepods (e.g. Hirche \& Kattner 1993), except for Euchaeta japonica (Lee et al. 1974).

The neutral buoyancy of Euphausia crystallorophias eggs is an obvious adaptation to the species' shelf habitat. Instead of spending their large wax ester reserves on an ascent from great depths, these energy depots can be invested into growth during the critical developmental period, through nauplius and metanauplius, when the larvae are still unable to feed. Hence, during this early ontogenetic period E. crystallorophias relies on internal energy stores, and its wax ester levels are strongly reduced until feeding starts in the calyptopis stage (Fevolden 1980). The low lipid contents of these early larvae enables them to survive for only 2 to 3 wk without food (Hagen 1988).

Further evidence for the life cycle strategies and trophic relationships of Euphausia crystallorophias may be derived from the type of storage lipids and from the fatty acid and alcohol compositions. Wax esters have been determined as the dominant depot lipid in E. crystallorophias (Bottino 1974, 1975, Clarke 1984, Hagen et al. 1996). In addition, phosphatidylcholine is deposited and may account for up to $40 \%$ of total lipid (Hagen 1988, Hagen et al. 1996). The primary storage of wax esters resembles the storage mode of Thysanoessa macrura but deviates completely from that of E. superba, which deposits triacylglycerols instead. On the other hand, the deposition of phosphatidylcholine is a characteristic of all 3 Antarctic euphausiids (Hagen et al. 1996).

The deposition of wax esters increases from the early developmental stages towards the adult stage, but apart from this ontogenetic accumulation, Euphausia crystallorophias also shows a pronounced seasonal increase in wax esters. In the larvae the fatty acid compositions reflect the dietary input more strongly as compared to the older stages. This is very similar to the lipid characteristics in Thysanoessa macrura (Hagen \& Kattner in press). Especially for the furciliae trophic marker, fatty acids suggest a stronger reliance on diatoms in spring, due to elevated amounts of the 16:1(n-7) fatty acid (Graeve et al. 1994). In contrast, higher concentrations of $18: 4(n-3)$ indicate that flagellates are the dominant food in summer and autumn. These dietary characteristics weaken in the older stages, which either indicates the diminished ingestion of phytoplankton or the intensified modification of these trophic markers.

\section{Lipid biosynthesis}

The most remarkable feature of the postlarval stages of Euphausia crystallorophias is the overwhelming dominance of the 18:1 fatty acids in the wax ester fraction, as reported earlier by Bottino $(1974,1975)$. Our analyses revealed that the $18: 1$ fatty acid is present in the 2 isomers, (n-9) and (n-7), which occur in a ratio between 3 and 4 to 1 . The preponderance of these isomers is exceptional in the zooplankton community and comparable only to the northern krill Thysanoessa inermis (Ackman et al. 1970, Sargent \& Falk-Petersen 1981, Saether et al. 1986). Their wax ester compositions are very similar, except that the 14:0 alcohol is dominant in E. crystallorophias, whereas the 16:0 alcohol predominates in $T$. inermis.

Although belonging to different genera, Euphausia crystallorophias and the Arctic Thysanoessa inermis exhibit more similarities with respect to their lipid compositions than $T$. inermis and its Antarctic congener T. macrura. In E. crystallorophias 18:1 fatty acids are strikingly dominant, whereas in $T$. macrura the 18:1 alcohols show a unique prevalence (Kattner et al. 1996, Hagen \& Kattner in press). The almost exclusive incorporation of the 2 isomers of the 18:1 fatty acid into the wax esters suggests a very selective biosynthetic pathway. It should be borne in mind, however, that both isomers have different precursors: $18: 1(n-9)$ is a desaturation product of the 18:0 fatty acid, whereas the $(n-7)$ isomer is probably elongated from the 16:1(n-7) precursor. The rather high proportion of the 18:1(n-7) 
fatty acid in the wax esters and in the triacylglycerols indicates an extensive conversion of $16: 1(n-7)$ into $18: 1(n-7)$. The $16: 1(n-7)$ fatty acid is generally assumed to originate from the phytoplanktonic diet.

The less elaborate wax ester biosynthesis (as compared to herbivorous copepods; Kattner \& Hagen 1995) is also reflected in the alcohol composition of Euphausia crystallorophias. The 14:0 alcohol comprises twothirds of the total alcohols. The corresponding fatty acid occurs only in trace amounts, which implies that the 14:0 fatty acid is largely reduced to alcohol for the wax ester biosynthesis. In contrast, the huge amounts of 18:1 fatty acids are not converted into alcohols, as is the case in Thysanoessa macrura (Kattner et al. 1996). Nothing is known about the biochemical mechanisms responsible for this kind of selection. Henderson et al. (1981) concluded from studies on $T$. inermis that fatty alcohols of wax esters are preferentially biosynthesised de novo, whereas fatty acids derive preferentially from dietary lipids, although this is not an exclusive mechanism. If the $18: 1(\mathrm{n}-9)$ fatty acid originates from the food of E. crystallorophias, then its feeding behaviour must be mainly omnivorous or even carnivorous, because this fatty acid is abundant in metazoans and detritus but scarce in phytoplankton. In spite of its omnivorous feeding mode we conclude that considerable lipid biosynthetic processes, de novo or via dietary fatty acid precursors, also take place in E. crystallorophias, due to the extreme accumulation of the 18:1(n-9) fatty acid.

The fatty acid composition of the triacylglycerols in the postlarval stages of Euphausia crystallorophias is clearly different from that of the wax esters. The 18:1 fatty acids are also the major components, but 16:0 and the trophic marker fatty acids indicate the preferred incorporation of dietary lipids into triacylglycerols. In the younger stages the compositions of both neutral lipid classes are more similar, suggesting a less developed ability for lipid biosynthesis. The phospholipid compositions are comparable to those of other zooplankton organisms (Albers et al. 1996) but again with a higher proportion of the 18:1 fatty acids, as also shown by Bottino (1975) for the individual phospholipid classes.

The fatty acid and alcohol compositions of Euphausia crystallorophias appear to be largely dependent upon the amounts of total lipid or wax ester present, as shown by their linear relationships. Its lipid accumulation is dominated by the fatty acid 18:1(n-9) and the alcohol 14:0. Linear characteristics are also found for the polyunsaturated fatty acids, although only the amount of the 20:5(n-3) fatty acid increases with increasing lipid content. Thus, the accumulation of phospholipids as depot lipid (Hagen et al. 1996) is mainly based on the production of this fatty acid. As found for Thysanoessa macrura (Hagen \& Kattner in press), the fatty alcohol regression lines calculated for Euphausia crystallorophias (independent of dry mass) indicate that wax esters are almost absent below a critical lipid level of about 8 to $9 \%$ DM, reflecting their function as depot lipid. Supportive evidence can also be derived from similar characteristics found for the accumulation of wax esters with total lipid levels in E. crystallorophias and T macrura (Hagen et al. 1996). This tendency is less pronounced for the two 18:1 fatty acid isomers, which together with their relatively high abundance in the phospholipids suggests that they have not only storage functions.

A common characteristic of the 3 dominant euphausiids is pronounced seasonal lipid accumulation as well as storage of phospholipids, whereas wax ester biosynthesis is found only in Thysanoessa macrura and Euphausia crystallorophias. In contrast to the triacylglycerol-depositing E. superba, the 2 wax ester-rich species spawn in late winter/early spring and use their lipid reserves to fuel reproductive processes. In spite of these similarities in T. macrura and E. crystallorophias, their fatty acid and alcohol compositions are considerably different, possibly reflecting their deviating ecological niches. This also emphasises the lipid biodiversity of polar zooplankton species, which exhibit a large variety of lipid biochemical adaptations to cope with the energetic constraints imposed upon them by their extreme high-Antarctic environment.

Acknowledgements. We are grateful to $\mathrm{A}$. Terbrüggen for excellent analytical work, to $\mathrm{H}$. Auel for assistance with the lipid extractions and to E. Mizdalski for sorting specimens. We thank the captains and crew of 'Polarstern' for their professional support. This is contribution no. 1437 of the Alfred Wegener Institute for Polar and Marine Research.

\section{LITERATURE CITED}

Ackman RG, Eaton CA, Sipos JC, Hooper SN, Castel] JD (1970) Lipids and fatty acids of two species of North Atlantic krill (Meganyctiphanes norvegica and Thysanoessa inermis) and their role in the aquatic food web. J Fish Res Bd Can 27:513-533

Albers C. Kattner G, Hagen W (1996) The compositions of wax esters, triacylglycerols and phospholipids in Arctic and Antarctic copepods: evidence of energetic adaptations. Mar Chem 55:347-358

Bottino NR (1974) The fatty acids of Antarctic phytoplankton and euphausiids. Fatty acid exchange among trophic levels of the Ross Sea. Mar Biol 27:197-204

Bottino NR (1975) Lipıd composition of two species of Antarctic krill: E. superba and E. crystallorophias. Comp Biochem Physiol 50B:479-484

Boysen-Ennen E, Hagen W, Hubold G, Piatkowski U (1991) Zooplankton biomass in the ice-covered Weddell Sea, Antarctica. Mar Biol 111:227-235

Brinton E. Townsend AW (1991) Development rates and habitat shifts in the Antarctic neritic euphausiid Euphausia crystallorophias, 1986-87. Deep-Sea Res 38:1195-1211 
Clarke A. (1980) The biochemical composition of krill, Euphausia superba Dana, from South Georgia. J Exp Mar Biol Ecol 43:221-236

Clarke A (1984) The lipid content and composition of some antarctic macrozooplankton. Br Antarct Surv Bull 63:57-70

Ellingsen TE, Mohr V (1981) Lipids in Antarctic krill. Composition and post mortem changes. In: Marcuse $\mathrm{R}$ (ed) Proc 11th Scand Symp on Lipids. SIK Gothenburg. Sweden, p 110-116

Fevolden SE (1980) Krill off Bouvetøya and in the southern Weddell Sea with a description of larval stages of Euphausia crystallorophias. Sarsia 65:149-162

Folch J, Lees M, Sloane-Stanley GH (1957) A simple method for the isolation and purification of total lipides from animal tissues. J Biol Chem 226:497-509

Graeve M, Kattner G, Hagen W (1994) Diet-induced changes in the fatty acid composition of Arctic herbivorous copepods: experimental evidence of trophic markers. J Exp Mar Biol Ecol 182:97-110

Hagen W (1988) Zur Bedeutung der Lipide im antarktischen Zooplankton. Ber Polarforsch 49:1-129 (English version 1989; On the significance of lipids in Antarctic zooplankton. Can Transl Fish Aquat Sci 5458:1-149)

Hagen W, Kattner G (1n press) Lipid metabolism of the Antarctic euphausiid Thysanoessa macrura and its ecological implications. Limnol Oceanogr

Hagen W, Van Vleet ES, Kattner G (1996) Seasonal lipid storage as overwintering strategy of Antarctic krill. Mar Ecol Prog Ser 134:85-89

Harrington SA, Thomas PG (1987) Observations on spawning by Euphausia crystallorophias from waters adjacent to Enderby Land (East Antarctica) and speculation on the early ontogenetic ecology of neritic euphausiids. Polar Biol $7: 93-95$

Hempel 1, Hempel G, Baker A De C (1979) Early life history stages of krill (Euphausia superba) in Bransfield Strait and Weddell Sea. Meeresforsch 27:267-281

Henderson RJ, Sargent JR, Falk-Petersen S (1981) Lipogenesis in the Arctic euphausiid Thysanoessa inermis. Mar Biol 63:235-240

Hirche HJ, Kattner G (1993) Egg production and lipid content of Calanus glacialis in spring: indication of a fooddependent and food-independent reproductive mode. Mar Biol 117:615-622

Hopkins TL (1987) Midwater food web in McMurdo Sound, Ross Sea, Antarctica. Mar Biol 96:93-106

John DD (1936) The southern species of Euphausia. Discovery Rep 14:193-324

Kattner G, Fricke HSG (1986) Simple gas-liquid chromatographic method for the simultaneous determination of fatty acids and alcohols in wax esters of marine organisms. J Chromatogr 361:263-268

Kattner G. Hagen W (1995) Polar herbivorous copepodsdifferent pathways in lıpid biosynthesis. ICES J Mar Sci 52:329-335

Kattner G, Hagen W, Falk-Petersen S, Sargent JR, Henderson RJ (1996) Antarctic krill Thysanoessa macrura fills a major gap in marine lipogenic pathways. Mar Ecol Prog Ser 134:295-298

Kirkwood JM (1996) The developmental rate of Euphausia crystallorophias larvae in Ellis Fjord, Vestfold Hills, Ant-

Editorial responsibility: Otto Kinne (Editor),

Oldendorf/Luhe, Germany arctica. Polar Biol 16:527-530

Kittel W, Ligowski R (1980) Algae found in the food of Euphausia crystallorophias (Crustacea). Pol Polar Res 1. 129-137

Lee RF, Nevenzel JC, Lewis AG (1974) Lipid changes during life cycle of marine copepod, Euchaeta japonica Marukawa. Lipids 9:891-898

Littlepage JL (1964) Seasonal variation in lipid content of two Antarctic marine Crustacea. In: Carrick R, Holdgate MW, Prévost J (eds) Biologie antarctique. 1er SCAR Symp, Hermann, Paris, p 463-470

Makarov RR (1979) Larval distribution and reproductive ecology of Thysanoessa macrura (Crustacea: Euphausiacea) in the Scotia Sea. Mar Biol 52:377-386

Marr JWS (1962) The natural history and geography of the Antarctic krill (Euphausia superba Dana). Discovery Rep $32: 33-464$

Marschall HP (1988) The overwintering strategy of Antarctic krill under the pack-ice of the Weddell Sea. Polar Biol 9: $129-135$

Mizdalski E (1988) Weight and length data of zooplankton in the Weddell Sea. Ber Polarforsch 55:1-72

Nicol S, De La Mare WK, Stolp M (1995) The energetic cost of egg production in Antarctic krill (Euphausia superba Dana). Antarct Sci $7: 25-30$

Nordhausen W (1994) Winter abundance and distribution of Euphausia superba, E. crystallorophias, and Thysanoessa macrura in Gerlache Strait and Crystal Sound, Antarctica. Mar Ecol Prog Ser 109:131-142

O'Brien DP (1987) Direct observations of the behavior of Euphausia superba and Euphausia crystallorophias (Crustacea: Euphausiacea) under pack ice during the Antarctic spring of 1985. J Crustac Biol 7:437-448

Pakhomov EA, Perissinotto R (1996) Antarctic neritic krill Euphausia crystallorophias: spatio-temporal distribution, growth and grazing rates. Deep-Sea Res 43:59-87

Pakhomov EA, Perissinotto R (1997) Spawning success and grazing impact of Euphausia crystallorophias in the Antarctic shelf region. In: Battaglia B, Valencia J, Walton DWH (eds) Antarctic communities: species, structure and survival. Cambridge University Press, p 187-192

Saether O, Ellingsen TE, Mohr V (1986) Lipids of North Atlantic krill. J Lipid Res 27:274-285

Sargent JR, Falk-Petersen S (1981) Ecological investigations on the zooplankton community of Balsfjorden, northern Norway: lipids and fatty acids in Meganyctiphanes norvegica, Thysanoessa raschu and $T$. inermis during midwinter. Mar Biol 62:131-137

Scharek R, Smetacek V, Fahrbach E, Gordon LI, Rohardt G, Moore S (1994) The transition from winter to early spring in the eastern Weddell Sea, Antarctica: plankton biomass and composition in relation to hydrography and nutrients. Deep-Sea Res 41:1231-1250

Siegel V (1987) A.ge and growth of Antarctic Euphausiacea (Crustacea) under natural conditions. Mar Biol 96:483-495

Stepnik R (1982) All-year populational studies of Euphausiacea (Crustacea) in the Admiralty Bay (King George Island, South Shetland Islands, Antarctic). Pol Polar Res 3: $49-68$

Zar JH. (1984) Biostatistical analysis. Prentice-Hall, Inc, Englewood Cliffs, NJ

Submitted: March 6, 1998; Accepted: June 8, 1998

Proofs received from author(s): July 27, 1998 